\title{
El retrato del obispo de Quito Pedro Ponce Carrasco en el Museo de América: ESTUDIO MONOGRÁFICO DE LA PINTURA
}

\author{
The portrait of the Bishop of Quito, Pedro \\ Ponce Carrasco in the Museum of America: \\ THE MONOGRAPHIC STUDY OF THE PAINTING
}

Ángel Justo Estebaranz

Universidad de Sevilla

Recibido: 31/03/2017 Evaluado: 24/06/2017 Aprobado: 04/07/2017

Resumen: En este trabajo se analiza el retrato del XVIII obispo de Quito, don Pedro Ponce Carrasco, realizado por Francisco Albán y su hijo en 1769 y actualmente conservado en el Museo de América de Madrid. Se estudia la composición de la pintura, las fuentes grabadas utilizadas por el artista, y también el sentido de la pintura, relacionándola con las particulares circunstancias en que se encontraba el retratado en el momento del encargo. Asimismo, se aporta documentación inédita sobre el proceso de adquisición del cuadro por parte del Museo de América a mediados del siglo xx.

Palabras clave: Obispo Pedro Ponce Carrasco, Francisco Albán, retrato, Quito, siglo XVIII

ABSTRACT: This paper analyzes the portrait of the XVIII bishop of Quito, Don Pedro Ponce Carrasco, painted by Francisco Albán and his son in 1769, and exhibited in the Museo de América (Madrid). We study the composition of the painting and the engraved source used by the artist. In addition, we study the meaning of the painting, relating it to the particular circumstances of the bishop at the time of the commission. Also, unpublished documents on the process of 
acquisition of the painting by the Museo de América in the middle of the 20th century are provided.

Keywords: Bishop Pedro Ponce Carrasco, Francisco Albán, portrait, Quito, XVIII century

Cl Museo de América conserva entre sus colecciones de arte virreinal una Einteresante pintura que representa al XVIII obispo de Quito, Pedro Ponce Carrasco. Este lienzo fue realizado por el pintor local Francisco Albán, a quien ayudaría su hijo, tal y como consta en la inscripción al pie de la pintura. A pesar de la relevancia del cuadro, su estudio apenas ha merecido la atención de los investigadores. Se han tratado aspectos parciales, como las joyas del obispo representadas en el lienzo, ${ }^{1}$ y se ha mencionado en diversas publicaciones, ${ }^{2}$ pero no se ha trabajado en profundidad ni su iconografía, ni el estilo del autor apreciable en la obra, ni las fuentes grabadas, ni la intención con que se realizó el cuadro. Asimismo, tampoco ha interesado a otros investigadores el periplo de la pintura hasta llegar a su actual ubicación. Al estudio de estos aspectos está dedicado este trabajo.

\section{Los protagonistas: el obispo Pedro Ponce y Carrasco y Francisco AlbÁn}

El personaje retratado en el cuadro del Museo de América, Pedro Ponce Carrasco, había nacido en 1703 en La Puebla de Guzmán -localidad de la comarca del Andévalo, Huelva-, fruto del matrimonio entre Rodrigo Ponce Carrasco y Fabiana García Hidalgo. Su formación se desarrolló en Sevilla, en cuya Facultad de Cánones debió empezar a estudiar hacia $1718 .{ }^{3}$ Se graduó de

1. Letizia Arbeteta Mira: «Precisiones iconográficas sobre algunas pinturas de la colección del Museo de América, basadas en el estudio de la joyería representada», Anales del Museo de América, 15 (2007), pp. 150-151.

2. ÂNGel Justo Estebaranz: «El clero se retrata: Imágenes de eclesiásticos quiteños durante el barroco», en Barroco iberoamericano: identidades culturales de un imperio, vol. I, Andavira Editora, Santiago de Compostela, 2013, pp. 49-50.

3. La formación sevillana de Pedro Ponce Carrasco debió de confundir al jesuita italiano Coleti y al quiteño Antonio de Alcedo, que se inspiró en el anterior, pues ambos señalaban que el prelado era natural de aquella ciudad. Además, lo identificaban como el XIX obispo de Quito, y no como el XVIII. Véase GiovanNI Domenico Coleti: Dizionario Storico-Geografico dell'America Meridionale, tomo II, Stamperia Coleti, Venecia, 1771, p. 109, y Antonio De AlCEDo: Diccionario geográfico-histórico de las Indias Occidentales ó América: es á saber: de los Reynos del Perú, Nueva España, Tierra Firme, Chile y Nuevo Reyno de Granada. Con la descripcion de sus provincias, naciones, ciudades, villas, pueblos, rios, montes, costas, puertos, islas..., vol. 4, Imprenta de Manuel González, Madrid, 1788, p. 385. Asimismo, Alcedo sostenía que el obispo había fallecido en 1776. La misma información se recoge en MANUEL ORTIZ DE LA VEGA: Los héroes y las grandezas de la Tierra, Librería de José Cuesta, Madrid, 1856, p. 604. Luque Alcaide yerra en las fechas que 
bachiller en el Colegio de Santa María de Jesús el 13 de enero de $1723 .{ }^{4}$ Dos años más tarde se recibía de abogado en la Real Audiencia de Sevilla. En 1732 acompañó en calidad de provisor al franciscano carmonense fray Juan Lasso de la Vega y Cansino a Santiago de Cuba, donde este había sido nombrado obispo. ${ }^{5}$ Allí desempeñaría el cargo de provisor y vicario general de la Diócesis de Cuba entre 1733 y 1747, y obispo Auxiliar de Santiago de Cuba con el título de Adramite entre 1747 y $1762 .{ }^{6}$ El 3 de febrero de 1761 se acordó nombrarlo obispo de Quito, ocupando la vacante desde septiembre de $1761 .^{7}$ No obstante, a la ciudad sudamericana llegaría en septiembre de 1764, y su episcopado se prolongaría hasta octubre de 1775 , año de su muerte. ${ }^{8}$ Con su nombramiento se puso fin a la vacante en la sede quiteña, que se había prolongado por tres años desde el fallecimiento del anterior obispo de Quito, don Juan Nieto Polo, en $1759 .{ }^{9} \mathrm{Su}$ episcopado no resultó apacible ni en lo político ni en lo eclesiástico. ${ }^{10}$ Eso sí, su papel como pacificador en la sublevación social contra la fiscalidad estatal en 1765 fue notable, mediante «persuasiones prudentes y llenas de suavidad», tal como él mismo reconocía en escrito enviado al Virrey. ${ }^{11}$

En Quito se pudo demostrar, como ya había sucedido en Cuba, que el genio del obispo Ponce era de naturaleza harto conflictiva, lo que le llevaría a enfrentarse con diversos miembros de la Administración. Este carácter se contradice con la semblanza que, en forma de carta al fiscal del Consejo de Indias, enviaba en julio de 1761 don Juan de Prado, gobernador de La Habana, quien

proporciona sobre su vida, ya que fija su nacimiento en Sevilla hacia 1722 y su deceso en 1776 . Véase ElisA LUQUE AlCAIDE: «Los concilios provinciales hispanoamericanos», en Teología en América Latina, vol. II/1, Iberoamericana-Vervuert, Madrid, 2005, p. 476.

4. Francisco NúÑEz Roldán: «Don Pedro Ponce Carrasco: Obispo de Cuba y Quito (1747-1775)», Actas de las XI Jornadas de Andalucía y América, tomo I, Diputación Provincial de Huelva, Huelva, 1993, p. 312.

5. Agi,Contratacion,5480,N.1,R.25, fol. 7 r. En este documento se indica que tiene 24 años, cuando según la fecha de nacimiento debieron ser 29. En la comitiva también iba Cristóbal Ponce Carrasco, de 54 años, natural de la Puebla de Guzmán. Este era fraile, e iba como confesor. Suponemos que este familiar sería quien se llevase al joven Pedro a Indias. En cuanto al futuro obispo de Quito, en este momento figuraba como licenciado. Véase Agi,Contratacion,5480,N.1,R.25, fol. 9 r.

6. NúÑEz RoldÁn: «Don Pedro Ponce Carrasco».pp. 309-312. Sabemos que en 1749 había visitado la iglesia parroquial de Trinidad, en Cuba, y en la documentación se le menciona como doctor y «dignísimo Obispo de Adramite», que «se portó como los anteriores» que habían visitado la iglesia. Véase Memorias de la Sociedad Patriótica de La Habana por una comisión permanente de su seno, tomo XII. Imprenta del Gobierno y Capitanía General por S. M., La Habana, 1841, p. 414.

7. José María Vargas: Historia de la Iglesia en el Ecuador durante el Patronato Español, Editorial «Santo Domingo», Quito, 1962, p. 397. En Cuba había sucedido a don Francisco de S. Buenaventura Tejada como obispo auxiliar. Véase ANtonio José VAldÉs: Historia de la isla de Cuba, y en especial de La Habana, vol. 1, Oficina de La Cena, La Habana, 1813, p. 371.

8. El Kalendario manual y guía de forasteros en Madrid se hacía eco de su dignidad y de la sede que ocupaba en sus ediciones de 1762, 1763, 1764, 1765, 1766, 1767, 1768, 1769, 1770, 1771, 1772, 1774, 1775 y 1776 quedando libre la de 1761, justo el año en que se nombra obispo de Quito. Es decir, que se recogía el nombramiento desde el año siguiente a la fecha de su publicación, y no desde el año en que ocupó personalmente la sede. Seguiría apareciendo como obispo un año después de muerto. Véase Kalendario manual y guía de forasteros en Madrid, D. Antonio Sanz, Madrid, 1767-1769, y Real Imprenta de la Gazeta, Madrid, 1769-1776, s. p.

9. NúÑEz RoldÁN: «Don Pedro Ponce Carrasco», pp. 332-333.

10. Ídem, p. 338.

11. Citado por NúÑEz Roldén: «Don Pedro Ponce Carrasco», p. 340. 
alababa al prelado como un ejemplo de virtud y de carácter pacífico. ${ }^{12}$ El carácter conflictivo y beligerante del prelado se pondría de manifiesto en Quito no solo contra los funcionarios de la Real Audiencia, sino también contra algunos eclesiásticos. El obispo e historiador Federico González Suárez destaca ciertas disputas mantenidas con canónigos quiteños, pues el Cabildo, desde el mismo momento de su entrada en la ciudad de Quito, le plantó batalla. ${ }^{13}$ Además, en 1769 , año de realización del retrato que analizamos, fue «escandalosamente faltado» por el provincial de La Merced, lo que supondría el destierro de este último. ${ }^{14}$ No obstante, González Suárez presenta a Ponce como un personaje excepcional «que, aunque no hagan daños por los cuales merezcan el aborrecimiento de sus súbditos, tampoco derraman beneficios por los cuales se granjeen el amor y el cariño de ellos», así como «anciano, grave y austero con los demás, amigo del encierro y muy consagrado al estudio, pudiendo decirse que murió con el libro en la mano». Este autor indica que testó más de cuatrocientos mil pesos, de los cuales cien mil se encontraron guardados en sus arcas en moneda sellada. ${ }^{15}$

En cuanto al autor del retrato del prelado, Francisco Albán, perteneció a una familia que contó entre sus miembros con varios artistas dedicados a la pintura. Los de mayor fama son los hermanos Francisco y Vicente, autores de diversas obras conocidas desde hace décadas, muchas de ellas conservadas en Quito y algunas en España. El padre Vargas identificaba a dos miembros más, ambos religiosos, que se dedicaron, al menos puntualmente, al arte de la pintura: fray Antonio Albán y fray Juan Albán, activos en la misma época que los dos anteriores -desde mediados de siglo hasta el último tercio-. ${ }^{16}$ Vicente

12. La cita completa es la siguiente: «En dicho Prelado he reconocido, sobre una exemplar virtud y retiro digno de su eminente carácter, un genio dozil, humilde pacífico y muy apropósito para mayores destinos, siendo tanta la veneración en que le tiene aquel Pueblo que no hay en él Noble ni Plebeyo que no se haga lenguas en aplauso de sus circunstancias. En varios asuntos que me pareció tratar con él por su larga experiencia en esta Ysla, me descubrió una muy bien dirigida capacidad y suma inclinación a sostener la Real Autoridad en todas sus partes, deduciendo para esto tan naturales y sólidas razones que al mismo tiempo que me imponía de su acertado modo de discurrir, me aseguraba en el concepto de su ánimo desapasionado y justo. Me atrevo a decir a V.E. que si todos los prelados que la Yglesía tiene en estos Reynos pensasen y procediesen como el Dr_ Dn. Pedro Ponce y Carrasco, con mucha más satisfacción servirían sus empleos los gobernadores y menos recursos llegarían a L.P. de S.M». Citado por NúÑEZ RoLDÁN: «Don Pedro Ponce Carrasco», p. 336.

13. Federico GonzÁlez SuÁrez: Historia general de la República del Ecuador, tomo V, Imprenta del Clero, Quito, 1901, p. 272. Al parecer, el obispo onubense exigía que se le tributaran los homenajes a los que tenía derecho, según las prescripciones del ceremonial de los obispos y del Pontifical Romano, pero los canónigos se los negaban, alegando ciertos privilegios del Cabildo y antiguas costumbres de la Catedral, que no habían sido contradichas por los obispos predecesores.

14. GonZÁlez SuÁREZ: Historia general, p. 277.

15. Ibidem, pp. 276-277.

16. José María VArgas: El arte ecuatoriano, Biblioteca Ecuatoriana Mínima, Quito, 1960, pp. 210-211 y JosÉ MARÍA VARGAS: El arte quiteño en los siglos XVI, XVII y XVIII, Litografía e Imprenta Romero, Quito, 1949 , p. 128. Si bien en estas publicaciones señala que el primero era mercedario, en otros textos identifica a ambos religiosos como pertenecientes a la orden dominica. Véase José MARía VARGAs: Arte quiteño colonial, Quito, 1944, p. 156; José MARÍA VARGAS: Historia de la cultura ecuatoriana, Casa de la Cultura Ecuatoriana, Quito, 1965, p. 452, y Hernán Crespo Toral y José María VArgas (coords.): Historia del arte ecuatoriano, tomo 3, Salvat Editores Ecuatoriana, S.A., Quito, 1977, p. 48. 
es el autor de la famosa serie de lienzos sobre los tipos de la Real Audiencia de Quito que, pintada en 1783, se conserva también en el Museo de América. Asimismo, realizó retratos de dignidades eclesiásticas quiteñas, como el retrato del obispo Blas Manuel Sobrino y Minayo, fechado también en $1783 .{ }^{17}$

La información acerca de la vida de Francisco Albán es realmente escasa hasta el momento. Según Pérez Pimentel, debió de nacer hacia $1720{ }^{18}$ Costales Samaniego cita un documento datado en 1754, en el que Francisco Albán aparece comprando una casa a doña María Casilda y a doña Dionicia Calvache, en el quiteño barrio de San Roque. ${ }^{19}$ Por su parte, el padre jesuita Juan de Velasco nombra en su Historia del Reino de Quito, escrita a fines del siglo XVIII, a un Maestro Albán, nativo de Quito, a quien tuvo la ocasión de conocer, y que puede ser Francisco. Asimismo, señalaba que varias obras de este fueron llevadas por los jesuitas a Italia, donde causaron una gran admiración. ${ }^{20}$ Según Vargas, es posible que Francisco Albán pudiese haber conocido al pintor Nicolás Javier de Goríbar. ${ }^{21}$ Francisco Albán debió de gozar en vida de fama y prestigio entre los comitentes de mayor relevancia de Quito. Además del testimonio de Velasco, coetáneo del pintor, existen en diferentes iglesias y museos varias pinturas que acreditan su trabajo para las grandes órdenes religiosas establecidas en la ciudad. Hasta el momento se han podido identificar varias pinturas, algunas pertenecientes a series que realizó para órdenes religiosas. Pero su labor no se limitó en exclusiva a la pintura de asunto religioso, pues también cultivó el retrato de las élites quiteñas, como demuestra el lienzo del Museo de América. La primera obra firmada por Francisco es una pintura de la Virgen de Aránzazu, fechada en 1747, que Vargas encontró en la Galería Windsor de Montevideo. ${ }^{22}$ Tres lustros más tarde, Francisco Albán figuraba entre los pintores más acreditados de la ciudad

Rodríguez Castelo consideraba a Francisco Albán como el integrante más importante de un taller en el que trabajaban varios hermanos, entre los que citaba a Vicente, y también a Juan y Carlos. Véase HeRNÁN Rodríguez CAstelo: Panorama del arte, Corporación Editora Nacional, Casa de la Cultura Ecuatoriana y Editorial El Conejo, Quito, 1993, p. 84.

17. VARgas: Arte quiteño, p. 156.

18. Rodolfo Pérez Pimentel: Diccionario biográfico del Ecuador, tomo 11, p. 1. <http://www. diccionariobiograficoecuador.com/tomos/tomo11/a1.htm> (consultada el 26/03/2017).

19. Alfredo Costales Samaniego: «El arte en la Real Audiencia de Quito. Artistas y artesanos desconocidos de la 'Escuela quiteña'», en Arte colonial quiteño. Renovado enfoque y nuevos actores, FonsAL, Quito, 2007, p. 236.

20. Juan De Velasco: Historia del Reino de Quito en la América meridional, tomo II y parte III, Imprenta del Gobierno, Quito, 1842, p. 61. Esta admiración con que en Italia se contemplaban las pinturas de Albán, puesta de manifiesta por Velasco, también se aplicaba al caso de Miguel de Santiago, de quien el jesuita y antes Jorge Juan y Antonio de Ulloa decían en la época que sus pinturas eran estimadas en Roma. Véase Jorge Juan y Antonio De Ulloa: Relación histórica del viage a la América meridional, Primera Parte, tomo I, Antonio Marín, Madrid, 1748, p. 365. Más allá de si este dato es cierto -la presencia real de obra de estos pintores en Roma y su aprecio en tierras transalpinas-, resulta de interés por ver cómo se trata de valorar el arte quiteño por el efecto causado en la Meca del Arte.

21. VARGAS: El arte quiteño, p. 127.

22. La inscripción era: «Aparición de Nuestra Señora de Aránzazu por Francisco Albán. 1747. Tacunga». Según el historiador dominico, esta obra en cobre procedía de Europa. Véase VArgas: Historia de la cultura, p. 450. En otra publicación adelantaba dos años la fecha del cuadro. Véase VArgas: El arte ecuatoriano, p. 209. 
andina, siendo requerido por miembros de las élites para realizar obra de asunto religioso, pero también algún retrato. Así, entre 1760 y 1764 realiza la serie de los Ejercicios espirituales para la Casa de Ejercicios, convertida en noviciado de los jesuitas. Las pinturas, que se conservaban en la Casa de Ejercicios del Tejar hasta que a fines del siglo xx pasaron al Palacio Arzobispal. ${ }^{23}$ fueron costeadas, según Vargas, por los ejercitantes más fervorosos. ${ }^{24} \mathrm{El}$ historiador ecuatoriano señala una tendencia hacia el uso de colores puros desvaídos que se habría iniciado precisamente con esta serie de Albán. ${ }^{25}$ Su relación con las órdenes religiosas quiteñas fue fructífera, pues en años sucesivos trabajó para los mercedarios, quienes le encargaron varias pinturas sobre san Pedro Nolasco, y para los dominicos, con una serie sobre la vida de santo Domingo para adornar el claustro. Según Vargas, ambos conjuntos fueron realizados en 1783 y 1788, respectivamente. ${ }^{26}$ Por su parte, Costales Samaniego cita a Albán como autor de las escenas del Viejo y el Nuevo Testamento de la iglesia del Sagrario de Quito. ${ }^{27}$ Esta fluida relación con las órdenes religiosas, y sobre todo el éxito alcanzado en la interpretación de los Ejercicios Espirituales, le debió de situar en un lugar privilegiado entre los artistas quiteños, en una posición que llamaría la atención del prelado Ponce. Más aún cuando entre los comitentes de esa serie figuraba el doctor don Gregorio Freire, canónigo de la Catedral de Quito, quien costeó un lienzo fechado en 1763. El de Ponce Carrasco no fue el único retrato de obispos de Quito que pintaron los Albán, pues Vicente retrató de medio cuerpo a Blas Sobrino y Minayo. Quizás, el éxito logrado con estas pinturas les permitiera gozar de la confianza de las autoridades para pintar los Tipos de la Real Audiencia, que finalizaría Vicente en los años ochenta.

\section{El retrato del Museo de América}

El lienzo del Museo de América fue pintado por Francisco Albán e hijo en 1769, durante el quinto año de presencia en Quito del prelado andaluz, quien llegaba a la capital de la Real Audiencia procedente de Cuba. La pintura está firmada, en latín, en el margen inferior derecho de la cartela: Fran[cis]cus Albán et filius eiunt fecerunt anno 1769 Quiti. ${ }^{28}$ La opción de firmar en latín

23. VArgas: Arte quiteño, p. 156, las vio en la Casa de Ejercicios. Según Pacheco Bustillos, tras la expulsión de los jesuitas, los ocho lienzos pasaron a ser propiedad de la corona española bajo la Junta de Temporalidades, entregándose a la Casa de Ejercicios de la Ermita de San José, en el retiro mercedario de Quito, en 1786. Véase Adriana Pacheco Bustillos: «Los Ejercicios Espirituales de San Ignacio de Loyola, 1760-1764», en The Art of Painting in Colonial Quito. El arte de la pintura en Quito colonial, Saint Joseph's University Press, Filadelfia, 2012, p. 182.

24. VARGAS: Historia de la Iglesia, p. 396, consigna el nombre del donante y el año de cada pintura.

25. VARGAS: El arte ecuatoriano, p. 210.

26. VARGAS: El arte quiteño, p. 128

27. Costales Samaniego: «El arte en la Real Audiencia de Quito», p. 236

28. En el trabajo Ángel Justo Estebaranz: «Arte quiteño en España», en Arte quiteño más allá de Quito, Fonsal: Quito, 2010, p. 300, tratamos brevemente sobre esta pintura. Citando a Martínez de la Torre y Cabello Carro, señalamos como fecha de realización 1738, pero es un error, pues al leer la inscripción 


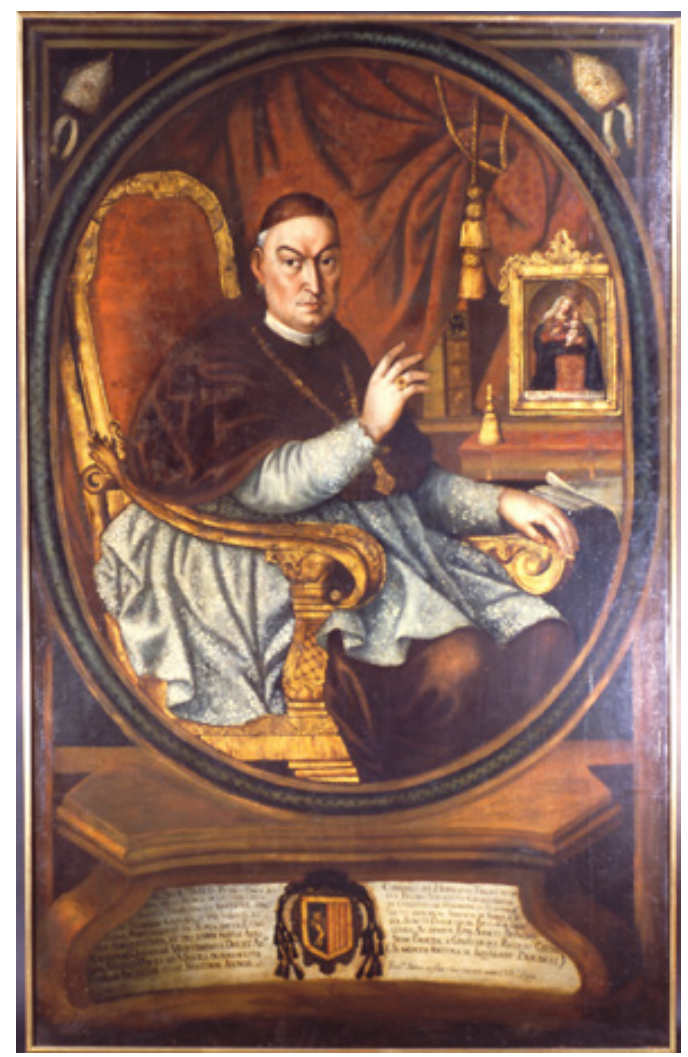

Fig. 1. Francisco Albán e hijo (firmado y fechado): Retrato del obispo Pedro Ponce Carrasco (1769, 167,5 x 106 cm, Museo de América, Madrid) y grabado de Giovanni Battista Sintes: Benedicto XIV (ca. 1740) que le sirvió como modelo

no fue un caso único en la obra de Albán, pues en otras de los años sesenta ya había consignado su nombre en dicho idioma. Es el caso del lienzo firmado perteneciente a la serie de los Ejercicios Espirituales, en el que firmó con la fórmula Fran. [cis]cus Alvan pinxit. ${ }^{29}$ Las dimensiones del retrato del obispo Pedro Ponce Carrasco (n. ${ }^{\circ}$ de inventario el 00070) son 1,675 x 1,06 m (fig. 1). En

del cuadro, la fecha correcta (1769) sí corresponde con la época de actuación de Francisco Albán y con el episcopado de Pedro Ponce en Quito. Véase: Cruz Martínez De La Torre y Paz Cabello Carro: Museo de América. Madrid, IberCaja, Zaragoza, 1997, p. 138.

29. Esta pintura, datada en 1760, fue sufragada por don Nicolás Pacheco, siendo diputado del Comercio, según figura en la inscripción alojada en la cartela de la zona inferior central.

Por su parte, su hermano Vicente usó la misma fórmula en otras pinturas, como el lienzo de la Crucifixión realizado en 1780 y actualmente conservado en el Museo Jijón y Caamaño de Quito. La firma exacta, Vicente Alban pinxit. a. 1780, aparece recogida en Crespo Toral y VARGAS (coords.): Historia del arte ecuatoriano, p. 48. 
el centro de la composición, el prelado aparece sentado, de tres cuartos, en el interior de su despacho. Parece haber sido interrumpido mientras se encontraba trabajando, pues sobre una mesa quedan varios pliegos de documentos y un cálamo. Se encuentra en actitud de bendecir al espectador, hacia quien gira su rostro dirigiendo una mirada penetrante. Se ha representado a la edad de 66 años. Viste ropajes propios de su dignidad eclesiástica, como también lo son las joyas que exhibe: el anillo episcopal y la cruz pectoral, que según Arbeteta corresponde a un tipo que se labró en el Virreinato del Perú. ${ }^{30}$ Gracias a los inventarios elaborados a la muerte del prelado sabemos que poseía cinco pectorales de oro, entre ellos uno con amatistas y cadena de oro, y otro con esmeraldas. ${ }^{31}$ Quizás alguno de estos dos sea el que aparece en el retrato. Más difícil de identificar sería el anillo, ya que se contabilizaron diecinueve sortijas en su poder. ${ }^{32}$

Para componer la pintura, Francisco Albán siguió de cerca el grabado que había realizado el artista italiano Giovanni Battista Sintes representando al papa Benedicto XIV, ${ }^{33}$ según el retrato pintado por el francés Pierre Subleyras al comienzo del papado (fig. 2). ${ }^{34}$ Tanto la temática como la composición de la estampa resultaron de gran utilidad a Albán, pues la filiación respecto a su modelo es muy clara. Son numerosas las ideas que el pintor quiteño tomó prestadas para su retrato del obispo Ponce respecto al modelo italiano. Así, la posición del pontífice, muy similar, ocupando una gran parte del encuadre.

30. Arbeteta Mira: «Precisiones iconográficas», p. 150. Esta investigadora señala que es de Perú de donde proceden la mayoría de ejemplares de estas cruces conservadas en la Península. En relación a la cruz representada en la pintura, es una pieza sólida, «con el frente cuajado por una retícula de piedras», y pie en losange. Por su parte, según esta investigadora, la cadena sería obra oriental.

31. Agi,Quito,331,N.45, fol. $31 \mathrm{v}$.

32. Agi,Quito,331,N.45, fol. 32 r. Según Morales y Marín, el anillo episcopal significa la señal de la unión del obispo con la Iglesia, unión contraída por la elección, ratificada por la confirmación o institución del soberano pontífice y confirmada por la consagración del elegido. Véase José Luis Morales y Marín: Diccionario de iconología y simbología, Taurus Ediciones, SA, Madrid, 1986, p. 45. Tal como indicaba el Papa Gregorio IV en su De culta pontificum, el prelado de Quito porta el anillo en su mano derecha, y concretamente en el dedo anular

33. Giovanni Battista Sintes (o Sintos) fue un grabador romano que vivió entre 1680 y 1760 . Fue discípulo de Benoit Farjat. Véase: Georg Kaspar Nagler: Neues Allgemeines Künstler-Lexikon, vol. 18, Schwarzenberg \& Schumann, Leipzig, 1900?, p. 480, y Ulrich Thieme y Felix Becker: Allgemeines Lexikon der Bildenden Künstler von der Antike bis zur Gegenwart, vol. XXXI, Verlag von E. A. Seemann, Leipzig, 1937, p. 93.

34. La misma pintura de Subleyras grabó también Rocco Pozzi, grabador italiano conocido por haber realizado varias estampas para el Museo Florentino, así como para la obra Antiquities of Herculaneum. Tras haber trabajado para el virrey de Nápoles, falleció hacia 1780. Por su parte Subleyras (1699-1749) fue un pintor francés formado en París y Roma, ciudad donde se estableció definitivamente, siendo autor de diversos retratos. Véase MiCHAEL BRYAN: Dictionary of painters and engravers, biographical and critical, vol. II, George Bell and Sons, London, 1889, pp. 318 y 545. En relación al retrato del papa, existen varias réplicas autógrafas del mismo realizadas por Subleyras, entre ellas las del Palacio de Versalles y del Museo Condé de Chantilly. Véase Francesco Petrucci: «Papal Portraiture Since the 16th Century», en Papi in Posa. 500 years of Papal Portraiture, Gangemi Editore, Roma, 2005, p. 40. Sabemos que el obispo Ponce tuvo a la vista esta estampa, pues conservaba en su biblioteca los tomos del bulario en que aparece. El grabado de Pozzi también se empleó en América. De hecho, en 1752 ya lo había utilizado en la Nueva España fray Miguel de Herrera, quien siguió muy de cerca el modelo en el retrato del papa Benedicto XIV que se conserva en el Museo Nacional del Virreinato (Tepotzotlán, México), en una obra, por lo demás, de limitadas cualidades plásticas. 


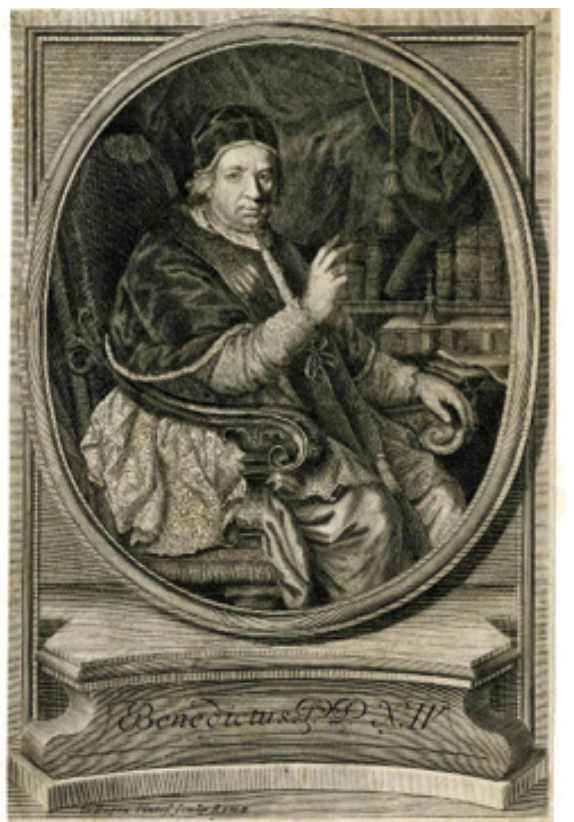

Fig. 1. Francisco Albán e hijo (firmado y fechado): Retrato del obispo Pedro Ponce Carrasco (1769, 167,5 x 106 cm, Museo de América, Madrid) y grabado de Giovanni Battista Sintes: Benedicto XIV (ca. 1740) que le sirvió como modelo

También son parecidos tanto el sillón, colocado en tres cuartos, ${ }^{35}$ como la disposición tras el retratado de un voluminoso cortinaje, recogido por un cordón dorado terminado en un gran borlón. El cortinaje deja entrever un anaquel con diversos libros -interpretados en este caso con lomos ricamente decorados de maneras variadas, distanciándose de su modelo en la homogeneidad de aquellos- dispuestos de tal modo que se subraye su condición de hombre de letras, a lo que se sumaría la inscripción en latín. No es menos importante el detalle de la campanilla, que ya figuraba en el retrato del Pontífice, si bien en el cuadro del Museo de América esta descansa directamente sobre el tapete, prescindiendo del lujoso tintero representado en el retrato de Benedicto XIV (fig. 3). También son parecidos los pliegos sobre la mesa. Albán ha incluido además una pequeña pintura de la Virgen con el Niño, que supone una novedad iconográfica. Se trata de la Virgen de la Peña, patrona de

35. La filiación del sillón respecto a la estampa es muy clara. De todas maneras, en los inventarios realizados a la muerte del obispo se cita «una silla de manos forrada de terciopelo carmesí con su flecadura de seda amarilla, y tachuelas de latón dorado, que pertenecía a la Dignidad». Véase Agi,Quito,331,N.45, fol. 40 r. Quizás posase el prelado sentado en esta silla, y se modificase de acuerdo con la que se muestra en el grabado. 


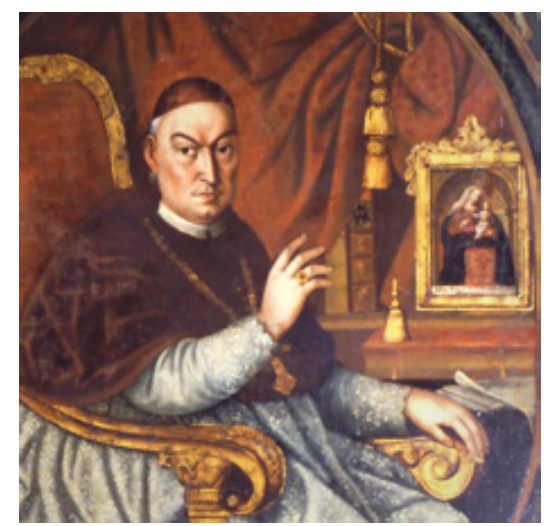

Fig. 3. Francisco Albán e hijo (firmado y fechado): detalle del Retrato del obispo Pedro Ponce Carrasco (1769, 167,5 x 106 cm, Museo de América, Madrid).

la Puebla de Guzmán, de la que el prelado era devoto. ${ }^{36}$ Probablemente sería esta una pintura devocional que llevó desde España hasta América, y que le acompañaría en sus diferentes destinos. ${ }^{37}$ Otros detalles son novedosos en la pintura: la sustitución del camauro que llevaba Benedicto XIV por el solideo del prelado onubense, y el pectoral en lugar de la estola.

En relación al cortinaje, vinculado con el retrato de aparato y que en la Europa barroca fue habitual, el que aparece en la pintura del Museo de América reviste cierta novedad. No es el primero pintado en un retrato quiteño, pues pocos años antes se pintó el de don Clemente Sánchez de Orellana (1763, Museo de la Medicina, Quito). Su utilización en el retrato de obispos se generalizó en Quito justo antes de su episcopado, pues en el episcopologio de la Sala Capitular de la catedral se incluyó la gran cortina roja recogida a la izquierda del obispo Juan Nieto Polo del Águila, su antecesor. El retrato de Ponce Carrasco allí conservado, al que haremos mención luego, guarda grandes similitudes con los de este y su sucesor (Blas Sobrino y Minayo, XIX obispo), y supondrían una excepción durante la segunda mitad del siglo XVIII, pues hasta el retrato del obispo Arteta y Calixto no aparecería de nuevo en la serie catedralicia. En

36. La inscripción a los pies de este cuadro es la siguiente: «Nuestra Sra de la Peña de Puebla de Guzman».

37. En los inventarios no se alude específicamente a esta pintura, sino a varias de tema religioso, entre ellas «doce cuadros pequeños con molduras doradas de distintas advocaciones que dijeron los señores diputados ser pertenecientes al Palacio» en el cuarto de la librería. Véase Agi,Quito,331,N.45, fol. $39 \mathrm{v}$. De todas maneras, no sería extraño que pudieran haberse equivocado al identificar esta pintura como perteneciente al palacio y no al obispo, y que no hubiesen identificado la advocación de la Virgen representada en la pintura, por ser de procedencia onubense y ámbito local. Tanto el formato de la pintura como el marco dorado y su ubicación en la librería podrían indicar que estuviese efectivamente allí. 
el caso del obispo Ponce Carrasco, sabemos que en el cuarto de la librería tenía cortinas de damasco carmesí. ${ }^{38}$ Quizás quisiera aparecer delante de su librería en el retrato, con las mismas cortinas, aunque el tono carmesí es habitual en el retrato de aparato.

El obispo Ponce conservaba un bulario del papa Benedicto XIV, aparecido en 1746 y editado en Roma por la Congregación de Propaganda Fide. ${ }^{39}$ En los inventarios efectuados tras la muerte del prelado hemos localizado este bulario, en tres tomos in folio. ${ }^{40}$ Esta obra debió de permanecer en poder del obispo al menos desde un tiempo antes de realizada la pintura y hasta su muerte, pero no era suya, sino del señor prebendado doctor don Juan Gregorio Freyre, quien no la había recuperado a la muerte de Ponce. ${ }^{41}$ La obra contaba con un magnífico grabado de Rocco Pozzi. Probablemente Ponce Carrasco vería en el retrato del papa al hombre sabio y sensato cuya imagen pretendía transmitir él mismo. Era el santo padre, en palabras del marqués de Caracciolo, que lo conoció, hombre «siempre zeloso y siempre moderado, siempre laborioso y siempre contento, siempre pontífice y siempre amable, siempre popular y Soberano siempre». Además, indicaba más adelante algo de lo que a buen seguro le gustaría presumir a Ponce: «amado tanto de los Protestantes, quanto de los Católicos, tanto del pueblo, quanto de los Reyes». ${ }^{42}$

Pero teniendo este grabado a la vista, el comitente prefirió otra de las estampas que reproducían el cuadro de Subleyras. Eligió la de Giovanni Battista Sintes, por una clara razón. Siguiendo la solución adoptada por este grabador romano, el pintor quiteño decidió enmarcar al prelado español en un óvalo, colocando bajo el mismo, y dando una sensación de trampantojo, un basamento que incluyó su escudo y una larga inscripción, al final de la cual aprovechó para firmar y fechar la pintura. Era esta la solución más adecuada, si se compara con el grabado de Pozzi, para dar relevancia a dicha inscripción. Esta forma de enmarcar el retrato fue muy frecuente, sobre todo en la estampa, como puso de manifiesto Gállego. ${ }^{43}$

Con la presentación del retrato en un óvalo superpuesto a un marco rectangular se introduce el juego del cuadro dentro del cuadro -juego, por lo

38. Agi,Quito,331,N.45, fol. 39 r

39. Sanctissimi domini nostri Benedicti papae 14. Bullarium Tom. 1. in quo continentur constitutiones, epistolae Ec. editae ab initio pontificatus usque ad annum 1746. Sacrae Congregationis de Propaganda Fide, Roma, 1746.

40. Agi,Quito,331,N.45, fol. 43 r. La referencia textual es «Benedicto Catorce en tres tomos de a folio. bulario». Además, tenía un «Benedicto Catorce de Sínodo en dos tomos» y un «Concilio Romano de Benedicto Catorce en un tomo», ambos en cuarto.

41. Agi,Quito,331,N.45, fol. 244 r. Que este personaje aparezca en estas circunstancias resulta muy interesante, pues en 1763 había costeado uno de los cuadros de Francisco Albán pertenecientes a la serie sobre los Ejercicios espirituales. Quizás este comitente pudo jugar un papel de introductor del pintor al obispo, pues era canónigo de la catedral, y habría quedado satisfecho con el resultado de la pintura. Además, fue quien le prestó al prelado el bulario que contenía el grabado del papa.

42. MARqués de CARACCIOlO: Vida del papa Benedicto XIV (Próspero Lambertini): con su retrato, y una breve descripcion de la Italia por manera de introducción, Imprenta de Benito Cano, Madrid, 1788, pp. XX-XXI y 1.

43. Julián GÁllego: El cuadro dentro del cuadro, Ediciones Cátedra, SA, Madrid, 1978, p. 186. 
demás, muy barroco, por su carácter de trampantojo, pero poco cultivado en Quito-.$^{44}$ En el caso quiteño, se suma un nivel más: el de la pintura de la Virgen de la Peña, con el Niño en brazos, que figura en último plano, a la derecha. En este caso, tenemos un cuadro dentro de un cuadro dentro de otro cuadro, cada uno con su propio marco, lo que supone un refinamiento muy singular en la pintura quiteña del momento, poco afecta a este tipo de sutilezas. Tal cual se puede observar en este lienzo, el óvalo apoya en el marco rectangular, y el marco dorado queda detrás. No obstante, la opción de dorar el marco del cuadro de la Virgen con el Niño y no los otros dos anteriores, ornamentándolo además de manera más ostensible, provoca que este cobre una inmediata importancia a ojos del espectador. Además, la propia planificación de la iluminación de la escena incide en la importancia de la pequeña pintura colocada sobre la mesita. Si se compara con el grabado, y sobre todo, con la pintura que dio origen a este, el último plano recibe una mayor iluminación en la obra de Albán. Además, el pintor americano ha aprovechado la posición del sillón y de la mano derecha del protagonista del grabado para conducir la visión del espectador hacia el cuadro, aunque de forma muy discreta. Con este detalle, el artista ha propuesto un juego que pone de relieve la devoción del prelado onubense por la Virgen de la Peña, patrona de su localidad natal.

Es de gran interés la elección de unos marcos que, exceptuando el del cuadro de la Virgen, son de una gran sobriedad de líneas, sin concesiones a la decoración desbordante propia del rococó que ya empezaba a estar de moda en la pintura quiteña. De hecho, pocos años antes, Albán estaba realizando pinturas enmarcadas en una compleja maraña de rocallas, que servían para separar las diferentes escenas que integraban las pinturas de los Ejercicios espirituales, y que tuvieron una importancia capital en el Quito de la segunda mitad del siglo xviII. Estos marcos eran de procedencia augsburguesa, concretamente de los grabados de los Klauber y otros artistas de la misma escuela. Pero resulta significativo que en el caso del retrato del obispo Ponce se omitiera este tipo de marco, optando por una mayor simplicidad de líneas. Ello se debe a que el artista quiteño siguió la estampa italiana, aunque coloreando en un tono azul verdoso la moldura central del óvalo, lo que da una mayor riqueza al marco.

La paleta cromática elegida por Francisco Albán es ciertamente limitada, ciñéndose a tonos cálidos, en colores ocres, marrones, anaranjados, dorados y blancos. ${ }^{45}$ Lejos quedan otras interpretaciones más atrevidas en el uso del colorido a la hora de representar a prelados quiteños, como las conservadas

44. En un trabajo anterior ya advertimos el carácter de trampantojo de esta pintura. Véase JUSTO EstebaranZ: «Arte quiteño», p. 300. Gállego destacaba la inclusión de un marco pintado como un mecanismo que permitía al pintor mayores sutilezas que el parapeto, usado con anterioridad en la pintura europea. De esta manera, el marco, ya fuera real o pintado, es la perfección de la separación. Véase: Gállego: El cuadro, p. 184.

45. Esta reducida gama cromática ya se encontraba en el retrato del papa Benedicto XIV realizado por Subleyras. 
del obispo Blas Sobrino y Minayo, sucesor de Ponce Carrasco, alguna de ellas realizada por su hermano Vicente. ${ }^{46}$

Nada queda en este retrato al margen de una interpretación concreta y pensada. Los espacios triangulares, que aparecen en la parte superior de la pintura por la colocación del óvalo sobre el marco rectangular, han sido ocupados por dos mitras episcopales. Estas, que son una novedad respecto al grabado italiano, aluden directamente al desempeño del obispado de Ponce en Cuba primero -en calidad de obispo auxiliar- y en Quito después, al momento de pintarse el retrato. En relación a la campanilla que figura sobre la mesa, este objeto tenía una larga trayectoria en el retrato de prelados desde el siglo XVI. ${ }^{47}$ Panofsky veía en ella un símbolo de nivel social, junto a otros que podían incluir estos retratos de dignidades eclesiásticas. ${ }^{48}$ La que aparece en este retrato podría ser una de las que poseía el prelado, pues en el inventario elaborado a su muerte se nombran tres, una de plata y dos doradas, como esta, aunque formando parte de «una tabla de vinajeras» (probablemente, una salvilla con vinajeras y campanilla a juego) y de un platillo con vinajeras, campanilla y cucharita dorado, respectivamente. ${ }^{49}$ Los libros y los papeles del cuadro, por su parte, hacen alusión directa a su condición de hombre de letras, de probada capacidad intelectual.

El retrato del obispo parece obedecer a una fuerte intención realista. El prelado andaluz se representa como un hombre de edad avanzada -concretamente, de 66 años-, con calvicie muy acusada y un rostro avejentado. Poco o nada queda de la descripción que se proporcionaba de él en la licencia de pasajeros a Indias, cuando era un joven «de buen cuerpo, cerrado de barba pelinegro de cara redonda $»^{50}$. La efigie que muestra el cuadro de Albán debe de corresponderse con la verdadera apariencia del obispo durante su estancia en Quito, pues se asemeja a otro retrato del mismo, conservado en la Sala Capitular de la Catedral de Quito y de autor anónimo, que parece realizado unos pocos años antes, quizás por el mismo Albán. Este retrato forma parte del episcopologio quiteño. En él, cada prelado se muestra de pie, siguiendo un esquema que se repite con variantes. En el caso del obispo Ponce aparecen igualmente las cejas arqueadas, la nariz alargada, el semblante serio y la frente despejada, así como un rostro inteligente que parece escrutar al espectador. En ambas pinturas lleva la misma cruz pectoral. No quedan ahí las coincidencias, pues ambos retratos incluyen la mitra episcopal, así como diversos libros -que no se muestran en otros retratos de obispos quiteños-,

46. Por ejemplo, la que conserva el Museo de América (número de inventario 2006/05/01), fechada en 1783, donde aparece el cortinón rojo que ya había utilizado Francisco, destinado aquí a resaltar al prelado, vestido de negro, sobre el fondo oscuro.

47. Gonzalo Martínez del VAlle: La imagen del poder. El retrato sevillano del siglo XVII, Fundación Real Maestranza de Caballería de Sevilla, 2010, p. 220.

48. Erwin Panofsky: Tiziano. Problemas de iconografía, Ediciones Akal, Madrid, 2003, p. 98.

49. Agi,Quito,331,N.45, fol. $32 \mathrm{v}$

50. Agi,Contratacion,5480,N.1,R.25, fol. 7 r 
alusivos a su condición de hombre culto y consagrado al estudio, como indicaba González Suárez. De los retratos conservados en la catedral de Quito, el del obispo Ponce Carrasco es el que más libros incluye, mientras que otros, como los retratos de los obispos Sobrino y Minayo o Pérez Calama, prescinden por completo de los libros. Pero curiosamente, Vargas indica que Ponce Carrasco no cursó estudios académicos, lo cual es incierto, pues más arriba hemos tenido ocasión de señalar sus estudios en Sevilla. ${ }^{51}$ Además, el obispo atesoraba al final de su vida una extensa librería jurídica, como indica Núñez Roldán ${ }^{52}$-pero no solo jurídica, pues también tenía multitud de volúmenes de asunto religioso- a la que hace mención expresa el lienzo del Museo de América.

El retrato que el prelado onubense mandó pintar en 1769 a Francisco Albán no se realizó con ocasión del nombramiento del obispo -momento que hubiera tenido su lógica, para conmemorar el inicio de su episcopado, aunque es posible que el de la catedral de Quito sea de ese período-, pues este ocupó la plaza desde septiembre de 1764. El destino de la pintura pudo ser desde un primer momento España, más concretamente su localidad natal. Además, en la cartela inferior se ha incluido una breve descripción de su trayectoria, en latín y en letras capitales. ${ }^{53}$ Lo cierto es que la pintura tiene un claro sentido de presentación del obispo como personaje competente, con dotes de mando, cultura y fe inquebrantable, así como una gran capacidad de trabajo. Creemos que el año elegido tiene un sentido claro, que ha de buscarse en la confrontación que mantuvo en los meses anteriores con dos funcionarios. Según Núñez Roldán, el obispo onubense se enfrentó con dos visitadores reales, uno en 1767 y otro en 1769, el primero por cuestiones relativas a las obligaciones tributarias de los eclesiásticos seculares con la Real Hacienda y el segundo por el incumplimiento pastoral de los párrocos con sus feligreses indígenas. ${ }^{54}$ En el primer enfrentamiento, contra el oidor de la Real Audiencia de Quito, don Serafín de Veyán y Mola, contó con el apoyo del presidente, y prefirió mantener para su persona el favor del cuerpo eclesiástico, cuya conducta se había relevado totalmente irregular. Tras este enfrentamiento vino otro aún mayor: el que mantuvo con el visitador de las Cajas Reales, el fiscal don José de Cistué. Precisamente, en 1767 el fiscal Cistué dirigía un informe a la Corona

51. VARgas: Historia de la Iglesia, p. 397.

52. NúÑez Roldán: «Don Pedro Ponce Carrasco», p. 358.

53. «ILL ${ }^{M U S}$. ET R RUS D.D.D. PETRUS PONCE. ET CARRASCO EX HISPALENSI REGNO IN OPPIDO VULGO PUEBLA DE GUZMAN ORIUNDUS RECIUS ADUOCATUS GRANATENSIS RECTOR BENEFITIATUS ECCLESIE SANCTI CHRISTOPHORI HABANENSIS. PROVISSORIO VICARIUS GENERALIS PER VIGINTI. ET OCTO ANNORUM SPATIUM IN INSULA DE CUBA, POST MODUM IN SUPRA DICTA ECCLESIA SANCTI CHRISTOPHORI EPUS CONSEGRATUS[?] ADRAMITENSIS, ET PRO EADEM INSULA AUXILIARIS AC DEMUN EPUS SANCTI FRANCISCI CIVITATIS QUITENSIS MERETISSIMUS DEI.ET AP ${ }^{\text {CA }}$. SEDIS GRATIA, A CONSILIIS QUE REGIE ET CATHOLICA MAIESTATE ET AD MAYORA INAUGURATUS (SI MERITIS FORTUNA SE EQUALEM PRAEBEAT) UTINAM FALICITER VIVAT NESTORIS ANNOS». Agradezco a D. a Ana Zabía, Conservadora del Museo de América, su ayuda con la transcripción de la inscripción en latín.

54. NúÑEz RoldéN: «Don Pedro Ponce Carrasco», p. 347. 
en el que daba cuenta de los abusos de los curas del obispado de Ponce con los indios, señalando que «el estado eclesiástico de esta provincia necesita de la mayor reforma y de un Prelado más celoso». ${ }^{55}$ Como había sucedido en el enfrentamiento con Veyán, el obispo Ponce volvió a contar con el apoyo del grupo clerical. A este informe se puede añadir la carta que el virrey don Pedro Messía de la Cerda envió al Consejo sobre lo que estaba sucediendo en Quito, y que está fechada el 11 de diciembre de $1767 .{ }^{56}$ La causa se debió dilatar en el tiempo, pues aún en marzo de 1769 seguía candente el tema, ya que de esa fecha data una misiva del fiscal Cistué al virrey Messía de la Cerda quejándose de la actuación del prelado onubense. Por lo tanto, si tras los dos episodios de enfrentamiento su imagen como gestor había quedado dañada, con esta pintura aparecería como un obispo culto y bonancible.

El retrato, las joyas exhibidas y la campanilla dorada hacen referencia a la riqueza del obispo, que atestigua la gran cantidad de objetos valiosos que se encontraron en su residencia a su muerte. De lo que no se da testimonio en el retrato, obviamente, es de la fama de tacaño que, junto con la de hombre rico y poderoso, lo acompañaría en un futuro, como señala Núñez Roldán. ${ }^{57}$ Además, el retrato sirve, o probablemente el propio obispo Ponce así lo quería, como contrapeso a su acreditada fama de personaje conflictivo. ${ }^{58} \mathrm{De}$ hecho, resulta realmente llamativo que el modelo utilizado para este retrato fuera el del Papa Benedicto XIV, hombre de gran formación intelectual que destacó por haber gobernado los Estados de la Iglesia con sabiduría y moderación. ${ }^{59}$

\section{El cuadro en el Museo de AmÉrica}

No sabemos en qué momento llegó el cuadro a la Península. Lo que sí sabemos es que, al momento de realizarse el inventario de bienes del obispo recién fallecido, no se cita ningún retrato entre sus pertenencias. Probablemente lo encargase y lo enviase en vida. Las siguientes noticias que

55. Citado por NúÑEz RoldÁN: «Don Pedro Ponce Carrasco», pp. 355-356.

56. Según relata el virrey, «Un oficio tan legal, de práctica regular y moderado en vez de mover a aquel señor obispo a enmendar los defectos de omisión advertidos y experimentados cerca de un año y medio, en perjuicio de los Reales intereses y con desprecio de los ministros de S.M. sirvió de excitar los humos de su cólera y acrimonia de su genio, (según se deja comprender y se manifiesta de otras antecedentes noticias que tengo) poco inclinado al Servicio del Rey y en lugar de librar los auxilios justamente pedidos para la solución de las cantidades adeudadas, de atreverse, sin atención ni miramiento al carácter y alto grado de mi dignidad y empleos... ha pasado a zaherir de nuevo... al fiscal». Citado en NúÑEz RoldéN: «Don Pedro Ponce Carrasco», p. 357

57. NúÑEz Roldán: «Don Pedro Ponce Carrasco», p. 358.

58. Así lo asegura Núñez RoldÁn: «Don Pedro Ponce Carrasco», p. 335, a partir del estudio de su labor al frente de los dos obispados americanos.

59. O, como indicaba Marin Ducreux, «sabia y pacíficamente». Véase Gabriel Marin Ducreux: Historia eclesiástica general, ó, Siglos del christianismo: que contiene los dogmas, liturgia, disciplina, concilios... hasta el año de 1700, vol. 7, Cano, Madrid, 1805, p. 420. 
hemos localizado son ya del siglo xx. La pintura llegó al Museo de América en 1948, por vía de compra. En un completo expediente se detallan los pormenores de la adquisición. ${ }^{60}$ La pintura se hallaba depositada en el Museo Provincial de Bellas Artes de Huelva, y pertenecía a un particular -Antonio Pérez Vázquez-. La adquisición se pudo hacer gracias a la intervención del marqués de Lozoya, quien vio la pintura y tomó la acertada decisión de adquirir la pieza, además a un precio bajo, teniendo en cuenta el carácter excepcional de la pintura -son muy escasos los retratos quiteños conservados en España-, la autoría de un miembro de la familia Albán - de la que ya poseían la serie de Tipos de la Real Audiencia de Quito-, y la cantidad de detalles que complican un cuadro que vas más allá de la media de retratos quiteños dieciochescos.

El relato de los acontecimientos es el siguiente: en octubre de 1946, el marqués de Lozoya, director general de Bellas Artes.$^{61}$ comunicaba al director del Museo de América una orden del ministro por la que se decidía entregar la pintura -que se encontraba en el Museo de Huelva- al de América, por ser el «sitio apropiado». ${ }^{62}$ La entrega se haría en depósito. El 13 de diciembre, el subdirector del museo madrileño pedía que se mandase «a gran velocidad a este museo», y embalado debidamente..$^{63}$ El día 20, el director del Museo de Huelva pedía información sobre quién sería la persona encargada de firmar el acta de recepción del retrato, en cumplimiento de la disposición ministerial..$^{64}$ En carta a don Alejandro Herrero, arquitecto municipal y pariente del director del Museo de América, este le pedía afectuosamente en febrero de 1947 que fuera con un carpintero embalador y se encargase del embalaje y envío de la pintura, a porte pagado, así como de levantar el acta de entrega del cuadro con el director del Museo de Huelva.$^{65}$ Lo más interesante de la misiva es que indica que fue el marqués de Lozoya quien, en su último

60. Archivo del Museo de América (AMA), Expediente 5111/1948/20. El número de inventario es 00070. 61. El marqués ostentó el cargo de director general de Bellas Artes entre 1939 y 1951. Véase DALMiro DE la Válgoma y Díaz-Varela: «El Marqués de Lozoya en la Real Academia de la Historia», en $E l$ Marqués de Lozoya Grande de España. Gráficas Nilo, Madrid, 1976, p. 19.

62. Ama, Expediente 5111/1948/20, documento n. ${ }^{\circ}$ 1. Carta del director general de Bellas Artes al director del Museo de América. 10/10/1946. En la carta se indica que los gastos del traslado del cuadro al museo serían satisfechos por el de América. En este y otros documentos del expediente se menciona la obra como realizada por Francisco Albán y sus hijos en 1779.

La orden procedía del Ministerio de Educación Nacional, que en esa época ocupaba José Ibáñez Martín (1939-1951). Véase <http://humanidades.cchs.csic.es/ih/paginas/jrug/diccionario/titulares/index_titu. htm> (consultada el 29/03/2017).

63. Ama, Expediente 5111/1948/20, documento n. ${ }^{\circ}$ 2. Carta del subdirector del Museo de América al director del Museo Provincial de Bellas Artes de Huelva. 13/12/1946.

64. Ama, Expediente 5111/1948/20, documento n. ${ }^{\circ}$ 3. Carta del director del Museo Provincial de Bellas Artes de Huelva al subdirector del Museo de América. 20/12/1946.

65. AmA, Expediente 5111/1948/20, documento n. ${ }^{\circ}$ 4. Carta del director del Museo de América a D. Alejandro Herrero. 10/02/1947. El tono de la carta es familiar. De hecho, eran parientes. Se le indica que en la misma factura se incluyesen los gastos de embalaje y de envío, con el descuento del 1,30\% por pagos al Estado, haciendo factura por triplicado. 
viaje a Huelva, vio el cuadro en el Museo y se interesó por él, dando orden de traslado en depósito. El mismo día que mandaba la carta a Alejandro Herrero, el director del Museo de América enviaba otra a su homólogo de Huelva dándole noticia de la retirada del cuadro, que no corría prisa. Por eso, le indicaba que eligiese el mejor momento para ello. ${ }^{66} \mathrm{El} 18$ de febrero firmaban el acta de entrega de la pintura el director del Museo de Huelva, José Pablo Martínez Coto, y Alejandro Herrero, ${ }^{67}$ En carta de 7 de marzo, el director del Museo de América agradecía a Herrero las gestiones que había realizado para la llegada de la pintura a Madrid. ${ }^{68}$ Al día siguiente enviaba una carta el director del museo onubense a José Tudela - a quien identificaba erróneamente como director del Museo de América- indicando que ya había hecho entrega del cuadro. ${ }^{69}$ El 28 de marzo remitía el subdirector del museo madrileño al director general de Bellas Artes copia del acta de entrega del cuadro a Herrero. ${ }^{70}$ Ese mismo día, el subdirector escribía al director del Museo de Huelva indicando que la pintura había llegado dos días antes -el 26-, comprobando que no había sufrido ningún deterioro durante el traslado al Museo. ${ }^{71}$

Habrá que esperar al año siguiente para que se adquiera en propiedad el lienzo que, hasta entonces, había estado en depósito. En documento firmado el 1 de marzo de 1948, el director general de Bellas Artes notificaba al director del Museo de América el ofrecimiento de venta al Estado que hacía Antonio Pérez Vázquez, propietario de la pintura, y pedía informe sobre esta petición

66. Ama, Expediente 5111/1948/20, documento n. ${ }^{\circ}$ 5. Carta del director del Museo de América al director del Museo Provincial de Bellas Artes de Huelva. 10/02/1947. El mismo día autorizaba el subdirector del Museo de América, José Tudela de la Orden, a Alejandro Herrero, para que recogiese el retrato. Véase AMA, Expediente 5111/1948/20, documento n. ${ }^{\circ}$ 6. Autorización del subdirector del Museo de América a Alejandro Herrero para que recoja el retrato del obispo Ponce Carrasco. 10/02/1947.

67. AmA, Expediente 5111/1948/20, documento n. ${ }^{\circ} 7$. Acta de entrega a Alejandro Herrero del retrato del obispo Ponce Carrasco. 18/02/1947. Una copia del acta quedaría en el museo onubense, otra iría al de América, y la tercera al Ministro de Educación Nacional. En el documento se indica que en la pintura se apreciaban deterioros debidos al tiempo. Por su parte, aparecen errores: se identifica al autor como «Francisco Altrán y sus hijos», y el año de 1779. En cuanto al retratado, aparece como obispo de La Habana, pero nada se dice de su episcopado quiteño.

68. Ama, Expediente 5111/1948/20, documento n. ${ }^{\circ}$ 8. Carta del director del Museo de América a D. Alejandro Herrero. 07/03/1947. Con la carta de Herrero había llegado copia del acta de entrega, así como la factura, habiéndose girado ya el importe al interesado al momento de escribir la carta. A pesar de su brevedad, la misiva tiene interés también por señalar que las previsiones del director en cuanto al avance de las obras del nuevo museo eran muy optimistas. Así, invitaba a Herrero a que viese el museo actual y las obras del nuevo, que pensaba que estarían muy avanzadas para el verano de ese año.

69. Ama, Expediente 5111/1948/20, documento n. ${ }^{\circ}$ 9. Carta del director del Museo Provincial de Bellas Artes de Huelva a D. José Tudela. 08/03/1947. En esta misiva sí aparece correctamente escrito el nombre de Francisco Albán.

70. AmA, Expediente 5111/1948/20, documento n. ${ }^{\circ}$ 10. Carta del subdirector del Museo de América al director general de Bellas Artes. 28/03/1947. En este texto figura correctamente el nombre de Francisco Albán.

71. Ama, Expediente 5111/1948/20, documento n. ${ }^{\circ} 11$. Carta del subdirector del Museo de América al director del Museo Provincial de Bellas Artes de Huelva. 28/03/1947. No está firmada, pero es a él a quien había escrito el director del museo onubense. 
y una valoración de la obra. ${ }^{72}$ Esta corrió a cargo del subdirector del Museo, y en ella ya constan correctamente el nombre del autor y el año de realización. ${ }^{73}$ El análisis que se hace de la pintura detalla medidas, composición y colorido. El autor del informe considera la pintura de aspecto arcaico por el dorado del sillón, del marco de la Virgen y de la campanilla sobre la mesa, así como «por la minuciosidad del dibujo de los encajes del roquete, muy del gusto de la escuela quiteña y que pasa después también en parte a la escuela de Charcas». Es interesante que se ponga de relieve el supuesto carácter indio del obispo -que en realidad era andaluz-, tanto por su color «como por la oblicuidad de sus ojos acentuada por el gesto de la frente», que le daría cierto carácter oriental y le haría parecer indígena. En realidad, esto no obedece a la intencionalidad del pintor, como indica el autor del texto. La necesidad de buscar una pintura que presentase rasgos «genuinamente» americanos explicaría esta interpretación, y no las características apreciables en el cuadro. En él se alaba también la armonía de color y la pátina dorada, que le confieren un encanto extraordinario. El subdirector atribuía erróneamente al mismo Francisco Albán los cuadros de los Tipos de la Real Audiencia de Quito, que son obra de su hermano Vicente. ${ }^{74}$ La tasación de la obra, en razón de sus dimensiones, calidad artística y prestigio de la firma, se hizo en «unas SEIS MIL pesetas». El mismo Subdirector remitía el informe al director general de Bellas Artes dos días después de su redacción. ${ }^{75}$

En julio de 1948 escribe el director general de Bellas Artes al del Museo de América dándole traslado de la comunicación del ministro en la que se indicaba la adquisición de la pintura por 6.000 pesetas. ${ }^{76} \mathrm{El}$ día 29, el subdirector del Museo mandaba certificado de que el cuadro se encontraba depositado y en buen estado de conservación, para que se abonase la cantidad acordada

72. AmA, Expediente 5111/1948/20, documento n. ${ }^{\circ}$ 12B. Notificación del director general de Bellas Artes al director del Museo de América. 01/03/1948. A la notificación se le dio salida el día siguiente, según consta en el sello.

Antonio Pérez Vázquez encabezaba en los años cincuenta el Juzgado Comarcal de Valverde. Véase <http://historiavalverde.blogspot.com.es/2013 0601 archive.html> (consultada el 10/12/2016). En esa localidad seguía a comienzos de los años setenta como juez de instrucción accidental de Valverde y su partido, según se recoge en el Boletín Oficial de la Provincia de Madrid, n. ${ }^{\circ}$ 61, sábado 11 de marzo de 1972, p. 7. Cómo pudo llegar a manos de Pérez Vázquez la pintura, y en qué momento concreto, es una cuestión que queda por resolver. No sabemos si en origen fue enviada a algún particular o a una iglesia -bien la de la Puebla de Guzmán, que sería lógico, bien a la de Valverde-, y de allí pasase a manos privadas en el siglo xx.

73. AmA, Expediente 5111/1948/20, documento n. ${ }^{\circ}$ 12A. Informe sobre el retrato del obispo Ponce Carrasco por el subdirector del Museo de América. 06/03/1948.

74. Y de la que en ese momento se exponían cuatro en la instalación provisional del museo.

75. AмA, Expediente 5111/1948/20, documento n. ${ }^{\circ}$ 13. Notificación del subdirector del Museo de América al director general de Bellas Artes. 08/03/1948.

76. AмA, Expediente 5111/1948/20, documento n. ${ }^{\circ}$ 14. Notificación del director general de Bellas Artes al director del Museo de América. 19/07/1948. El pago se haría «con cargo al crédito de quinientas mil consignado en el capítulo $3 .^{\circ}$, artículo $4 .^{\circ}$, grupo $6 .^{\circ}$, concepto 13 , subconcepto $8 .^{\circ}$ "Adquisiciones de obras de arte y objetos arqueológicos» del vigente Presupuesto de gastos de este Ministerio», una vez que la dirección del museo hubiese certificado que la obra había sido entregada y quedase bajo su custodia y vigilancia. 
al anterior propietario. ${ }^{77} \mathrm{El}$ último documento del expediente es la carta del director general de Bellas Artes dando traslado de la comunicación del ministro. ${ }^{78}$ Este decidía a comienzos de agosto que se librase la cantidad acordada, dando fin a la operación de compra, que se había dilatado cinco meses.

En suma, el retrato mandado pintar por el obispo Ponce Carrasco a Francisco Albán supone una contribución única en la pintura quiteña, la más refinada muestra de la retratística eclesiástica virreinal en la capital de la Real Audiencia. En este cuadro, destinado probablemente a la Península, el anciano prelado se presentaba como un hombre probo. Aparece como una persona seria -así debía ser por la gravedad de la responsabilidad del cargo que ostentaba-, de recio carácter, que mira fijamente al espectador para hacerlo partícipe de su buen gobierno, como se lee en la inscripción de la peana. Pedro Ponce Carrasco aparece además como un prelado que ha desempeñado ese puesto en más de una ocasión -de lo que dan testimonio las dos mitras en los ángulos superiores-, siempre correctamente. A pesar de la larga ausencia de su tierra natal -había abandonado la Península en 1732-, no se olvida de su pueblo, como atestigua el cuadro de la Virgen de la Peña dispuesto sobre la mesa. El modelo utilizado es un papa cercano en el tiempo a su desempeño pastoral -Benedicto XIV-, de quien se utilizó una estampa de Sintes que lo presentaba sentado en su despacho y bendiciendo al espectador. La utilización de este referente obedeció al deseo del prelado onubense, quien tenía al Papa boloñés como referente.

El Marqués de Lozoya, director general de Bellas Artes, supo ver las cualidades de la pintura, y no dudó en ordenar su traslado al Museo de América. Sería una obra que completaría las colecciones de pintura quiteña, y un gran ejemplo de retrato de las élites pintado en Quito. La adquisición final de la pintura constituye un gran acierto de las autoridades.

\section{BibLIOGRAFíA}

Alcedo, Antonio de: Diccionario geográfico-histórico de las Indias Occidentales ó América: es á saber: de los Reynos del Perú, Nueva España, Tierra Firme, Chile y Nuevo Reyno de Granada. Con la descripcion de sus provincias, naciones, ciudades, villas, pueblos, rios, montes, costas, puertos, islas..., vol. 4, Imprenta de Manuel González, Madrid, 1788.

Arbeteta Mira, Letizia: «Precisiones iconográficas sobre algunas pinturas de la colección del Museo de América, basadas en el estudio de la joyería representada», Anales del Museo de América, 15 (2007), pp. 141-171.

BRYAN, MICHAEL: Dictionary of painters and engravers, biographical and critical, vol. II, George Bell and Sons, Londres, 1889.

77. Ama, Expediente 5111/1948/20, documento n. ${ }^{\circ} 15$. Certificado del subdirector del Museo de América. 29/07/1948.

78. AmA, Expediente 5111/1948/20, documento n. ${ }^{\circ}$ 16. Notificación del director general de Bellas Artes al director del Museo de América. 05/08/1948. Según consta en los sellos del documento, se le dio salida el 13 de agosto, llegando al Museo de América el 14 de dicho mes. 
Caracciolo, Marqués de: Vida del papa Benedicto XIV (Próspero Lambertini): con su retrato, y una breve descripcion de la Italia por manera de introducción, Imprenta de Benito Cano, Madrid, 1788.

Coleti, Giovanni Domenico: Dizionario Storico-Geografico dell'America Meridionale, tomo II, Stamperia Coleti, Venecia, 1771.

Costales Samaniego, Alfredo: «El arte en la Real Audiencia de Quito. Artistas y artesanos desconocidos de la «Escuela quiteña»», en Arte colonial quiteño. Renovado enfoque y nuevos actores, FONSAL, Quito, 2007, pp. 125-315.

Crespo Toral, Hernán y Vargas, José María (coords.): Historia del arte ecuatoriano, tomo 3, Salvat Editores Ecuatoriana, SA, Quito, 1977.

Gállego, Julián: El cuadro dentro del cuadro, Ediciones Cátedra, SA, Madrid, 1978.

GonzÁlez SuÁrez, Federico: Historia general de la República del Ecuador, tomo V, Imprenta del Clero, Quito, 1901.

Juan, Jorge y UlloA, Antonio De: Relación histórica del viage a la América meridional, primera parte, tomo I, Antonio Marín, Madrid, 1748.

Justo Estebaranz, Ángel: «Arte quiteño en España», en Arte quiteño más allá de Quito, FONSAL, Quito, 2010, pp. 295-311.

- «El clero se retrata: Imágenes de eclesiásticos quiteños durante el barroco», en Barroco iberoamericano: identidades culturales de un imperio, vol. I, Andavira Editora, Santiago de Compostela, 2013, pp. 31-50.

Kalendario manual y guía de forasteros en Madrid, D. Antonio Sanz, Madrid, 1767-1769, y Real Imprenta de la Gazeta, Madrid, 1769-1776.

LuQue Alcaide, Elisa: «Los concilios provinciales hispanoamericanos», en Teología en América Latina, vol. II/1, Iberoamericana-Vervuert, Madrid, 2005, pp. 423-523.

Marin Ducreux, Gabriel: Historia eclesiástica general, ó, Siglos del christianismo: que contiene los dogmas, liturgia, disciplina, concilios... hasta el año de 1700, vol. 7, Cano, Madrid, 1805.

Martínez de la Torre, Cruz y Cabello Carro, Paz: Museo de América. Madrid, IberCaja, Zaragoza, 1997.

Martínez del Valle, Gonzalo: La imagen del poder. El retrato sevillano del siglo XVII, Fundación Real Maestranza de Caballería de Sevilla, 2010.

Memorias de la Sociedad Patriótica de La Habana por una comisión permanente de su seno, tomo XII. Imprenta del Gobierno y Capitanía General por S. M., La Habana, 1841.

Morales y Marín, José LuIS: Diccionario de iconología y simbología, Taurus Ediciones, SA, Madrid, 1986.

Nagler, Georg Kaspar: Neues Allgemeines Künstler-Lexikon, vol. 18, Schwarzenberg \& Schumann, Leipzig, 1900?.

Núñez Roldán, Francisco: «Don Pedro Ponce Carrasco: Obispo de Cuba y Quito (17471775)», Actas de las XI Jornadas de Andalucía y América, tomo I, Diputación Provincial de Huelva, Huelva, 1993, pp. 309-360.

Ortiz de la Vega, MANuel: Los héroes y las grandezas de la Tierra, Librería de José Cuesta, Madrid, 1856.

Pacheco Bustillos, Adriana: «Los Ejercicios Espirituales de San Ignacio de Loyola, 17601764», en The Art of Painting in Colonial Quito. El arte de la pintura en Quito colonial, Saint Joseph's University Press, Filadelfia, 2012, p. 182.

Panofsky, Erwin: Tiziano. Problemas de iconografía, Ediciones Akal, Madrid, 2003.

Pérez Pimentel, Rodolfo: Diccionario biográfico del Ecuador, tomo 11 . <http://www. diccionariobiograficoecuador.com/tomos/tomo11/a1.htm> (consultada el 26/03/2017).

Petrucci, Francesco: «Papal Portraiture Since the 16th Century», en Papi in Posa. 500 years of Papal Portraiture, Gangemi Editore, Roma, 2005.

Rodríguez Castelo, Hernán: Panorama del arte, Corporación Editora Nacional, Casa de la Cultura Ecuatoriana y Editorial El Conejo, Quito, 1993. 
Sanctissimi domini nostri Benedicti papae 14. Bullarium Tom. 1. in quo continentur constitutiones, epistolae Ec. editae ab initio pontificatus usque ad annum 1746. Sacrae Congregationis de Propaganda Fide, Roma, 1746.

Thieme, Ulrich Y BeCKer, Felix: Allgemeines Lexikon der Bildenden Künstler von der Antike bis zur Gegenwart, vol. XXXI, Verlag von E. A. Seemann, Leipzig, 1937.

VAldés, Antonio José: Historia de la isla de Cuba, y en especial de La Habana, vol. 1, Oficina de La Cena, La Habana, 1813.

VÁlgoma y Díaz-VArela, Dalmiro de la: «El Marqués de Lozoya en la Real Academia de la Historia», en El Marqués de Lozoya Grande de España. Gráficas Nilo, Madrid, 1976, pp. 1521

VArgas, José María: Arte quiteño colonial, Quito, 1944.

- El arte quiteño en los siglos XVI, XVII y XVIII, Litografía e Imprenta Romero, Quito, 1949.

- El arte ecuatoriano, Biblioteca Ecuatoriana Mínima, Quito, 1960.

- Historia de la Iglesia en el Ecuador durante el Patronato Español, Editorial «Santo Domingo», Quito, 1962.

- Historia de la cultura ecuatoriana, Casa de la Cultura Ecuatoriana, Quito, 1965.

Velasco, JuAn De: Historia del Reino de Quito en la América Meridional, tomo II y parte III, Imprenta del Gobierno, Quito, 1842. 
